\title{
Overexpression of MACC1 and the association with hepatocyte growth factor/c-Met in epithelial ovarian cancer
}

\author{
HONGYU LI, HUI ZHANG, SHUJUN ZHAO, YUN SHI, JUNGE YAO, \\ YANYAN ZHANG, HUANHUAN GUO and XINGSUO LIU \\ Department of Gynecological Oncology, The Third Affiliated Hospital of Zhengzhou University, \\ Zhengzhou, Henan 450052, P.R. China
}

Received December 22, 2013; Accepted August 1, 2014

DOI: $10.3892 / \mathrm{ol} .2015 .2984$

\begin{abstract}
Metastasis-associated in colon cancer-1 (MACC1) is a gene that has been newly identified by a genome-wide search for differentially expressed genes in human colon cancer tissues, metastases and normal tissues. MACC1 exerts an important role in colon cancer metastasis through upregulation of the c-Met proto-oncogene. The tyrosine kinase receptor encoded by the c-Met oncogene exhibits the unusual property of mediating the invasive growth of epithelial cells upon binding with the hepatocyte growth factor (HGF). MACC1 has been investigated with regard to colon carcinoma and MACC1 expression is associated with metastasis in various types of human cancer. However, the value of MACC1 as a potential biomarker for ovarian cancer remains unknown, although the c-Met/HGF receptor has been shown to be overexpressed in epithelial ovarian cancer tissues. To investigate the role of MACC1 in epithelial ovarian tumors, the expression levels of MACC1 mRNA in ovarian tumor specimens were analyzed together with the prognostic significance. MACC1 protein expression was also detected in the epithelial ovarian tissue specimens, and the effects of MACC1 overexpression on ovarian cancer migration, invasion and prognosis were evaluated. Due to the close association between MACC1 and c-Met expression levels in colon cancer, the expression levels of $\mathrm{HGF} / \mathrm{c}-\mathrm{Met}$ in the ovarian specimens were also examined to determine whether such a correlation is also present in epithelial ovarian cancer. A total of 92 epithelial ovarian tissue samples were used to assess the expression levels of MACC1 mRNA
\end{abstract}

Correspondence to: Miss. Hongyu Li, Department of Gynecological Oncology, The Third Affiliated Hospital of Zhengzhou University, 7 Kangfu Road, Zhengzhou, Henan 450052, P.R. China

E-mail: lihongyu99@qq.com

Abbreviations: MACC1, metastasis-associated colon cancer 1; HGF, hepatocyte growth factor; RT-PCR, reverse transcriptionpolymerase chain reaction; IHC, immunohistochemistry; ELISA, enzyme-linked immunosorbent assay

Key words: epithelial ovarian tumors, MACC1, c-Met, HGF, RT-PCR, IHC, ELISA and protein using reverse transcription-polymerase chain reaction and immunohistochemical methods, respectively. The serum levels of MACC1 protein expression in patients with epithelial ovarian cancer were detected by enzyme-linked immunosorbent assay. The results indicated that MACC1 may be important in the malignant progression of epithelial ovarian tumors, in particular for early stage patients. Thus, MACC1 may become a predictor of prognosis and a therapeutic target in the treatment of ovarian tumors. The combined detection of $\mathrm{MACC} 1$ and $\mathrm{HGF} / \mathrm{c}-\mathrm{Met}$ is therefore important in assessing the prognosis of patients with malignant epithelial ovarian tumors.

\section{Introduction}

Ovarian cancer is one of the most lethal types of malignant tumor in females, worldwide (1). It is the third most common type of cancer in females worldwide, following cervical cancer and endometrial cancer, and is the leading cause of fatalities from gynecological cancer (2). Due to the lack of effective screening strategies and the fact that the early stage of the disease is asymptomatic, $>70 \%$ of patients present at an advanced stage (3). Although there have been advances in surgical techniques and conventional chemotherapy, the prognosis of patients with ovarian cancer has not been evidently improved (3). The five-year survival rate in patients with epithelial ovarian cancer attending the Peking Union Medical College Hospital (Beijing, China) was $92 \%$ for stage I cancer, $72 \%$ for stage II, $42 \%$ for stage III and $18 \%$ for stage IV (4). At present, the aetiology of ovarian cancer remains poorly understood. The key signal transduction pathways implicated in the pathogenesis of ovarian cancer include the PI3K/Akt/mTOR signaling pathway, the Wnt/ $\beta$-catenin signaling cascade and the hepatocyte growth factor (HGF)/c-Met signaling pathway (5). Recently, numerous disorders associated with the deregulation of the HGF/c-Met axis have been reported $(6,7)$. Dysregulation of c-Met is common in ovarian cancer, although the exact mechanisms of this signaling pathway in the carcinogenesis of ovarian cancer remain under investigation.

Tumor metastasis is a complex multistep process in which tumor cells leave the original site, migrate into the lymphatic system or bloodstream, and then form secondary tumors in other parts of the body. Tumor metastasis is common in the late stages of cancer and is responsible for the majority of cancer fatalities. 
Molecularly, a number of genes are involved in the process of tumor metastasis, including the metastasis-associated in colon cancer-1 (MACC1) gene (8-10). The protein product of this gene, MACC1, was first identified through analysis of normal colon mucosae, primary and secondary colorectal cancer tissues, using differential-display reverse transcription-polymerase chain reaction (RT-PCR) $(11,12)$. A subsequent study found that expression of MACC1 protein in vitro promoted colon cancer cell migration and invasion, and HGF-induced tumor cell scattering (8). MACC1 was shown to induce tumor migration, invasion and proliferation in cell culture, as well as liver and lung metastases in several xenograft models $(12,13)$. In these models, MACC1 was observed to bind to the promoter of the receptor tyrosine kinase c-Met, transcriptionally regulating c-Met expression. MACC1-induced activation of the $\mathrm{HGF} / \mathrm{c}-\mathrm{Met}$ signaling pathway has been demonstrated to result in enhanced cell motility, invasion and metastasis $(11,14,15)$. These results indicate that MACC1 expression is important in cancer progression. Although a great deal of effort has been devoted to an improved understanding of the molecular pathogenesis and mechanisms of ovarian cancer metastasis, the high rates of recurrence signify a poor prognosis for patients with ovarian cancer. Preliminary studies have revealed that MACC1, HGF and C-Met may be expressed abnormally in ovarian cancer which may have an important role in the process of the occurrence and development of ovarian cancer $(12,16)$. Therefore, the value of MACC1 as a potential biomarker for epithelial ovarian cancer remains unknown.

In the present study, the expression levels and cellular locations of MACC1 and HGF/c-Met proteins in epithelial ovarian cancer specimens were evaluated and compared with those of benign epithelial ovarian and normal ovarian tissues. Subsequently, the expression levels of MACC1, HGF or c-Met mRNA were examined using RT-PCR. The serum levels of MACC1 protein expression in patients with epithelial ovarian cancer were evaluated with enzyme-linked immunosorbent assay (ELISA). The prognostic value of MACC1 detection in epithelial ovarian carcinoma was analyzed, and the associations between abnormal expression levels of MACC1, HGF and c-Met, and the clinical pathological features of epithelial ovarian cancer were evaluated. The interactions among these three molecules, and the subsequent effect on the development and prognosis of epithelial ovarian carcinoma are discussed.

\section{Materials and methods}

Sample collection. A total of 92 epithelial ovarian tissue samples were collected, consisting of samples from 20 patients with normal ovaries undergoing resection for non-oncological reasons (control group, group 1), 25 patients with ovarian benign epithelial tumors (group 2) undergoing ovarian cyst removal and 47 patients with ovarian malignant epithelial tumors (30 serous, 10 mucinous and seven endometrial samples; group 3) undergoing cytoreductive surgery. No statistically significant difference in terms of age was identified among the three groups $(\mathrm{P}>0.05)$. The 47 cases of epithelial ovarian cancer were selected from a larger series of tumors observed at the pathology department of the Third Hospital Affiliated of Zhengzhou University (Zhengzhou, China) between 2011 and 2013. Each specimen was cut into two sections immediately following surgery. One section was frozen in liquid nitrogen and stored at $-80^{\circ} \mathrm{C}$ for a time period ranging between three months and two years, until the sample was processed for RNA extraction. The adjacent portion of the tumor was fixed in $4 \%$ paraformaldehyde, embedded in paraffin and sectioned in accordance with standard procedures for conventional histology, Congo red staining and immunohistochemical characterization. Preoperative and postoperative sterile extraction of 3-4 ml peripheral blood using coagulant vacuum pick blood vessels was performed when patients had an empty stomach. Prior to full solidification, within $12 \mathrm{~h}$, the blood samples were centrifuged at $3,840 \mathrm{x} \mathrm{g}$, for $15 \mathrm{~min}$ at $4^{\circ} \mathrm{C}$, and the supernatant was then stored at $-80^{\circ} \mathrm{C}$. The Research Ethics Committee of the Medical College at the Third Hospital Affiliated of Zhengzhou University approved this study. Written informed consent was obtained from all patients.

Reagents. An immunohistochemical detection kit and the DAB kit were purchased from Beijing Zhongshan Jinqiao Biotechnology Co., Ltd (Beijing, China). Rabbit anti-human MACC1, HGF and c-Met polyclonal antibodies were purchased from Beijing Boosen Biological Technology Co., Ltd. (Beijing, China), while tRNA and TRIzol were purchased from Transgene (Strasbourg, France) and a OptiProtein marker was obtained from Applied Biological Materials Inc., (Richomnd, $\mathrm{BC}$, Canada). The primers were purchased from Beijing Boda Tektronix Inc. (Beijing, China), and the MACC1 ELISA kit was purchased from R\&D Systems (Minneapolis, MN, USA).

$R T$-PCR. Total RNA was isolated from the fresh frozen tissues using a Fastgen200 RNA isolation system (Fastgen, Shanghai, China) in accordance with the manufacturer's instructions (17). The RNA samples were then reverse-transcribed to cDNA with a Revert Aid Premium First Strand cDNA Synthesis kit (Thermo Fisher Scientific, Rockford, IL, USA). PCR amplification of the cDNA was performed at an initial temperature of $94^{\circ} \mathrm{C}$ for $5 \mathrm{~min}$ and then 30 cycles of $94^{\circ} \mathrm{C}$ for $30 \mathrm{sec}, 54^{\circ} \mathrm{C}$ for $30 \mathrm{sec}$ and $72^{\circ} \mathrm{C}$ for $30 \mathrm{sec}$, followed by a final extension at $72^{\circ} \mathrm{C}$ for $7 \mathrm{~min}$ using $2 \mathrm{X}$ Taq mix. The PCR products were then loaded into a $2 \%$ agarose gel for electrophoresis.

In addition, quantitative PCR was performed. The suitability of the RT reaction product for PCR amplification was first verified by conducting a PCR reaction for GAPDH cDNA. The primer sequences used for amplification of GAPDH can be found in Table I, along with those for MACC1, HGF and c-Met amplification (18). All samples were normalized to internal controls and fold-changes were calculated through relative quantification (Table II). The threshold cycle $(\mathrm{Ct})$ values for triplicate reactions were averaged and the relative genomic expression levels were calculated using the $2^{-\Delta \Delta \mathrm{Ct}}$ value $[\Delta \mathrm{Ct}=\mathrm{Ct}(\mathrm{MACC} 1)-\mathrm{Ct}(18 \mathrm{~s})](19)$. Melting curves were produced to ensure only a single product was amplified.

Immunohistochemistry (IHC). The sections were dewaxed and dehydrated, then incubated with a methanol solution containing $0.3 \%$ hydrogen peroxide for 30 min to block any endogenous peroxidase activity. Following antigen retrieval in a citrate buffer in a microwave for $15 \mathrm{~min}$, the sections were incubated with normal serum at $37^{\circ} \mathrm{C}$ for $30 \mathrm{~min}$, and then with the primary monoclonal antibodies against MACC1 or 
Table I. Primer sequences for reverse transcription-polymerase chain reaction.

\begin{tabular}{|c|c|c|c|c|}
\hline Gene & Forward primer ( $5^{\prime}$ to $\left.3^{\prime}\right)$ & Reverse primer ( $5^{\prime}$ to $\left.3^{\prime}\right)$ & $\begin{array}{c}\text { Annealing } \\
\text { temperature }\left({ }^{\circ} \mathrm{C}\right)\end{array}$ & $\begin{array}{c}\text { Product } \\
\text { length (bp) }\end{array}$ \\
\hline MACC1 & GAGCCACAATAAGTTCATACA & GAGCCACAATAAGTTCATACA & 54.0 & 315 \\
\hline HGF & TAGGCACTGACTCCGAACA & AGGAGATGCAGGAGGACAT & 53.0 & 136 \\
\hline c-Met & TTTAGGGACTCAGTTTCTTTAC & AACAGTTACTATGCAGGTTCAG & 54.0 & 253 \\
\hline GAPDH & AАATCCCATCACCATCTTCC & CCTGCTTCACCACCTTCTTG & 55.0 & 581 \\
\hline
\end{tabular}

MACC1, metastasis-associated in colon cancer 1; HGF, hepatocyte growth factor; bp, base pairs.

Table II. MACC1, HGF and c-Met mRNA expression levels in each group (mean \pm SD) determined by semi-quantitative reverse transcription-polymerase chain reaction.

\begin{tabular}{lccrc}
\hline Group & No. of samples & $\begin{array}{c}\text { MACC1 mRNA } \\
(\mu \mathrm{g})\end{array}$ & $\begin{array}{c}\text { HGF mRNA } \\
(\mu \mathrm{g})\end{array}$ & $\begin{array}{c}\mathrm{c}-\mathrm{Met} \text { mRNA } \\
(\mu \mathrm{g})\end{array}$ \\
\hline Epithelial ovarian carcinoma tissue & 47 & $0.428 \pm 0.077^{\mathrm{a}}$ & $0.356 \pm 0.061^{\mathrm{a}}$ & $0.751 \pm 0.152^{\mathrm{a}}$ \\
Benign epithelial ovarian tumor tissue & 25 & $0.182 \pm 0.021$ & $0.198 \pm 0.031$ & $0.253 \pm 0.043$ \\
Normal ovarian tissue & 20 & $0.099 \pm 0.013$ & $0.135 \pm 0.023$ & $0.166 \pm 0.026$ \\
\hline
\end{tabular}

${ }^{a} \mathrm{P}<0.05$ vs. normal and benign groups. MACC1, metastasis-associated in colon cancer-1; HGF, hepatocyte growth factor.

Table III. Positive expression rate of MACC1, HGF and c-Met proteins in different types of ovarian tissue.

\begin{tabular}{|c|c|c|c|c|c|c|c|c|c|c|c|c|c|}
\hline \multirow[b]{2}{*}{ Tissue type } & \multirow[b]{2}{*}{ No. } & \multicolumn{4}{|c|}{ MACC1 } & \multicolumn{4}{|c|}{ HGF } & \multicolumn{4}{|c|}{ c-Met } \\
\hline & & - & + & Positive rate $(\%)$ & $\chi^{2}$ & - & + & Positive rate $(\%)$ & $\chi^{2}$ & - & + & Positive rate $(\%)$ & $\chi^{2}$ \\
\hline Normal & 20 & 19 & 1 & 5.00 & 4.02 & 19 & 1 & 5.00 & 2.16 & 18 & 2 & 10.00 & 4.07 \\
\hline Benign & 25 & 18 & 7 & 28.00 & 11.78 & 20 & 5 & 25.00 & 12.55 & 16 & 9 & 36.00 & 11.48 \\
\hline Cancer & 47 & 14 & 33 & 70.21 & $23.87^{\mathrm{a}}$ & 17 & 30 & 63.80 & $19.53^{a}$ & 11 & 36 & 76.59 & $25.35^{\mathrm{a}}$ \\
\hline
\end{tabular}

${ }^{a} \mathrm{P}<0.05$ vs. normal and benign groups. MACC1, metastasis-associated in colon cancer-1; HGF, hepatocyte growth factor.

$\mathrm{HGF} / \mathrm{c}-\mathrm{Met}$ at $4^{\circ} \mathrm{C}$ overnight. The following day, the sections were washed with PBS and incubated with biotinylated goat anti-rabbit IgG secondary monoclonal antibodies (1:500; Beijing Boosen Biological Technology Co., Ltd, Beijing, China) and avidin-biotin-peroxidase complexes (AAT Bioquest Inc., Sunnyvale, CA, USA) for $30 \mathrm{~min}$ in accordance with the manufacturers' instructions. Positive signals were visualized by incubating the sections at $37^{\circ} \mathrm{C}$ for $40 \mathrm{~min}$ with a diaminobenzidine solution and counterstaining with hematoxylin. The sections were then dehydrated in an alcohol series, cleared in xylene, mounted onto glass slides and visualized using a microscope (CX31, Olympus Corporation, Tokyo, Japan).

ELISA. A double-antibody sandwich ELISA assay was conducted to detect the serum levels of MACC1. Purified human anti-human monoclonal MACC1 antibody was used to coat microtiter plate wells and produce a solid-phase antibody, then samples were added to the wells. Horse radish peroxidase (HRP)-labeled monoclonal anti-human MACC1 antibodies
(R\&D Systems, Minneapolis, MN, USA) were added to form antibody-antigen-enzyme-antibody complexes, subsequent to washing completely with poly-HRP-antibody conjugate complexes. 3,3',5,5'-tetramethylbenzidine substrate solution was added, which generates a blue color due to a reaction catalyzed by the HRP enzyme. The reaction was terminated by the addition of sulfuric acid solution and the color change was measured spectrophotometrically at a wavelength of 450 nm (UV-5800PC; Shanghai Metash Instruments Co., Ltd, Shanghai, China). The concentration of MACC1 in the samples was then determined by comparing the optical densities of the samples to the values on the standard curve.

Statistical analysis. All statistical analyses were performed using SPSS 17.0 software (SPSS, Inc., Chicago, IL, USA). All data are presented as the mean \pm standard deviation. The $\chi^{2}$ test and Fisher's exact test were used to compare frequencies. Spearman's correlation test was applied to analyze the correlations. Multiple group comparisons were achieved by one-way 
A

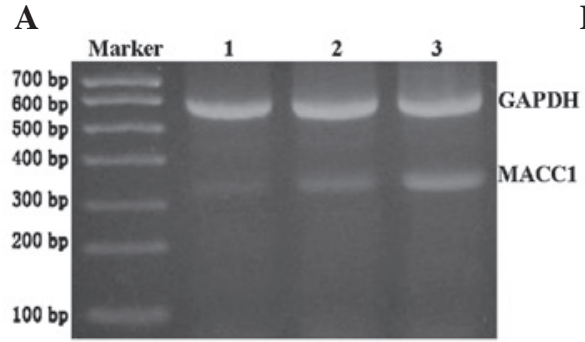

B

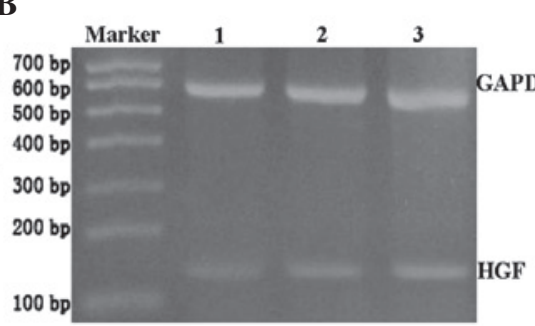

C

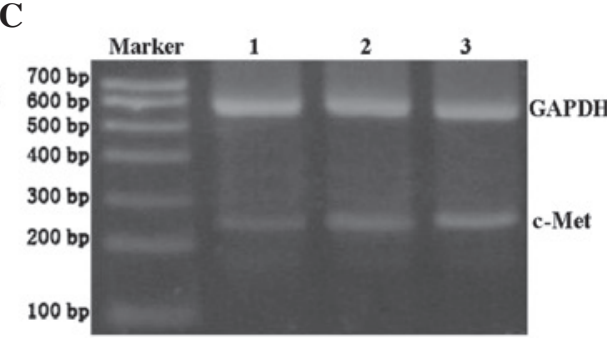

Figure 1. Representative reverse-transcription-polymerase chain reaction results for (A) metastasis-associated in colon cancer-1 (MACC1), (B) hepatocyte growth factor (HGF) and (C) c-Met in normal ovarian tissue (lane 1), benign epithelial ovarian tumor tissue (lane 2) and epithelial ovarian cancer tissue (lane 3). GAPDH was used as a loading control.
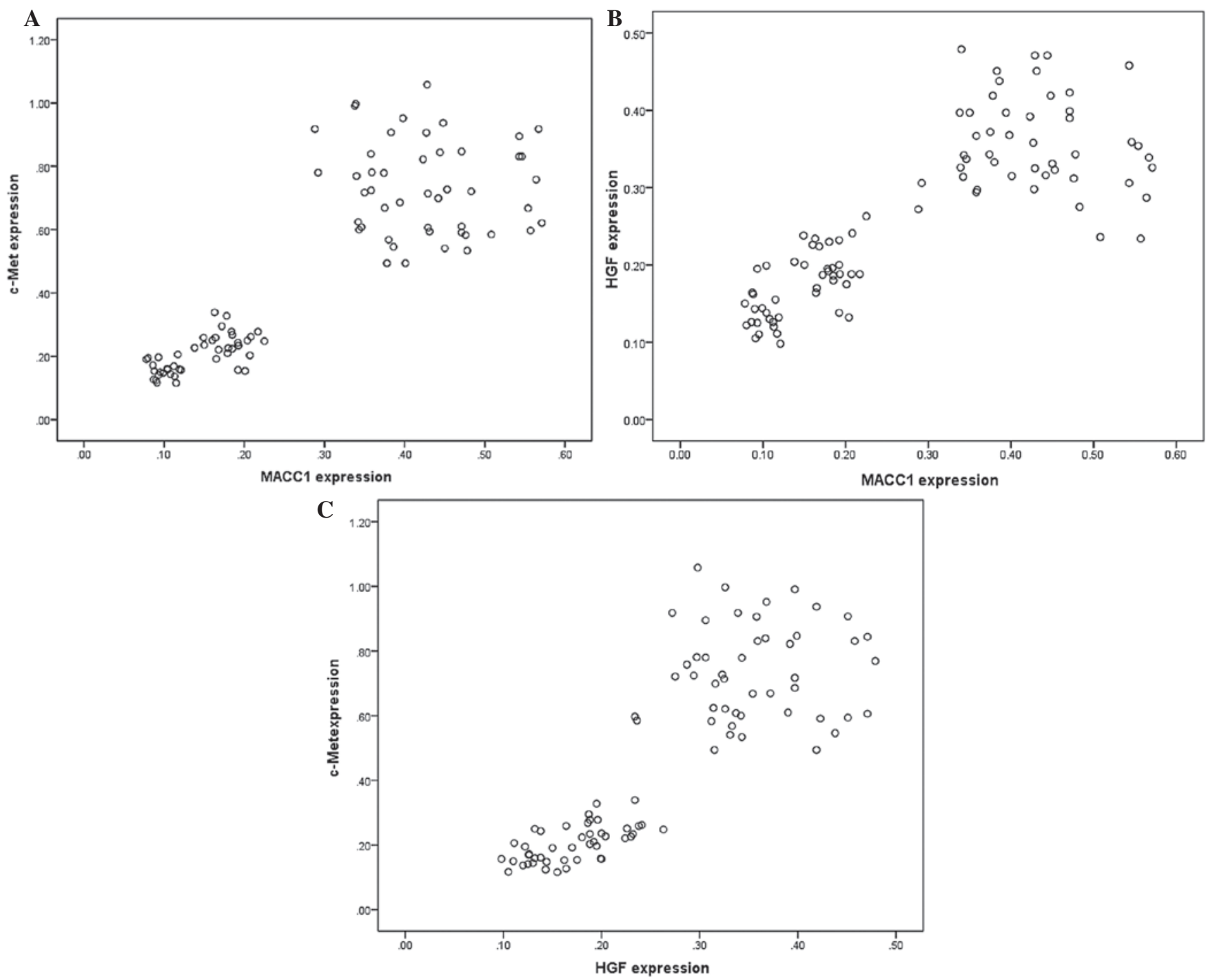

Figure 2. Comparative distribution of the expression levels of c-Met, hepatocyte growth factor (HGF) and metastasis-associated in colon cancer-1 (MACC1). Two-sample correlation plots of (A) c-Met and MACC1 expression levels $(r=0.849, \mathrm{P}<0.01)$, (B) MACC1 and HGF expression levels $(\mathrm{r}=0.810, \mathrm{P}<0.01)$ and (C) HGF and c-Met expression levels $(r=0.831, \mathrm{P}<0.01)$.

analysis of variance. All P-values were two-sided. $\mathrm{P}<0.05$ was considered to indicate a statistically significant difference.

\section{Results}

Differential expression levels of MACC1 $m R N A$ and HGF/c-Met mRNA in normal ovarian tissues. MACC1
mRNA expression levels were examined in three groups of ovarian tissues (Table II). RT-PCR revealed that MACC1 mRNA was expressed in all epithelial ovarian cancer, ovarian benign tumor and normal ovarian tissues (Fig. 1A). However, using relative expression quantity, the MACC1 mRNA expression levels were significantly higher in the epithelial ovarian carcinoma tissues than those in the 
Table IV. Associations between positive expression of MACC1, HGF and c-Met proteins, and clinical pathological features in epithelial ovarian cancer samples.

\begin{tabular}{|c|c|c|c|c|c|c|c|c|c|c|c|c|c|}
\hline \multirow[b]{2}{*}{ Clinical parameter } & \multirow[b]{2}{*}{ No. } & \multicolumn{4}{|c|}{ MACC1 } & \multicolumn{4}{|c|}{ HGF } & \multicolumn{4}{|c|}{ c-Met } \\
\hline & & + & - & $\chi^{2}$ & $\mathrm{P}$ & + & - & $\chi^{2}$ & $\mathrm{P}$ & + & - & $\chi^{2}$ & $\mathrm{P}$ \\
\hline Age (years) & & & & 2.805 & 0.094 & & & 1.124 & 0.289 & & & 0.567 & 0.451 \\
\hline$<45$ & 11 & 5 & 6 & & & 9 & 2 & & & 7 & 4 & & \\
\hline$\geq 45$ & 36 & 28 & 8 & & & 21 & 15 & & & 29 & 7 & & \\
\hline FIGO stage & & & & 3.861 & 0.049 & & & 4.573 & 0.032 & & & 7.074 & 0.008 \\
\hline $\mathrm{I}+\mathrm{II}$ & 10 & 4 & 6 & & & 3 & 7 & & & 4 & 6 & & \\
\hline $\mathrm{III}+\mathrm{I}$ & 37 & 29 & 8 & & & 27 & 10 & & & 32 & 5 & & \\
\hline Histological type & & & & 3.803 & 0.149 & & & 1.840 & 0.399 & & & 2.335 & 0.311 \\
\hline Serous & 30 & 24 & 6 & & & 21 & 9 & & & 25 & 5 & & \\
\hline Mucinous & 10 & 5 & 5 & & & 6 & 4 & & & 7 & 3 & & \\
\hline Endometrioid & 7 & 4 & 3 & & & 3 & 4 & & & 4 & 3 & & \\
\hline Histological grading & & & & 5.596 & 0.018 & & & 5.315 & 0.021 & & & 6.221 & 0.013 \\
\hline High & 30 & 17 & 13 & & & 15 & 15 & & & 19 & 11 & & \\
\hline Low & 17 & 16 & 1 & & & 15 & 2 & & & 17 & 0 & & \\
\hline Lymph node metastasis & & & & 7.373 & 0.007 & & & 6.207 & 0.013 & & & 9.232 & 0.002 \\
\hline Positive & 29 & 25 & 4 & & & 23 & 6 & & & 27 & 2 & & \\
\hline Negative & 18 & 8 & 10 & & & 7 & 11 & & & 9 & 9 & & \\
\hline
\end{tabular}

MACC1, metastasis-associated in colon cancer-1; HGF, hepatocyte growth factor.

benign epithelial ovarian tumor and normal ovarian tissues $(\mathrm{F}=295.032, \mathrm{P}<0.01)$. The HGF and c-Met mRNA expression levels in the three groups were detected with the same method (Fig. 1B and C). The results demonstrated that HGF and c-Met mRNA were expressed at significantly higher levels in the epithelial ovarian carcinoma tissues than in the benign epithelial ovarian tumor and normal ovarian tissues $(\mathrm{F}=177.252, \mathrm{P}<0.01$; and $\mathrm{F}=264.183, \mathrm{P}<0.01$, respectively).

Correlation between MACC1 and HGF/c-Met mRNA expression levels in ovarian tumors. To address whether MACC1 and $\mathrm{HGF} / \mathrm{c}-\mathrm{Met}$ mRNA expression levels were correlated, the qPCR results from the 92 cases epithelial ovarian tissue were analyzed. When the expression levels of MACC1 and $\mathrm{HGF} / \mathrm{c}-$ Met in these samples were plotted on a scatterplot diagram, a significant positive correlation between the expression levels of MACC1 and c-Met was detected (Pearson's correlation test, $\mathrm{r}=0.849, \mathrm{P}<0.01$; Fig. $2 \mathrm{~A})$. MACC1 expression levels were also positively correlated with those of HGF ( $\mathrm{r}=0.810, \mathrm{P}<0.01$; Fig. $2 \mathrm{~B}$ ), and the expression levels of HGF and c-Met were also positively correlated $(r=0.831$, $\mathrm{P}<0.01$; Fig. 2C).

MACC1 protein expression in three ovarian tissue groups. Immunostaining revealed that MACC1 protein was localized in the cell membrane and cytoplasm of epithelial ovarian tumors (Fig. 3). The positive expression rates of MACC1 (70.21\%), HGF $(63.80 \%)$ and c-Met $(76.59 \%)$ in epithelial ovarian carcinoma tissues were significantly higher than
Table V. Average preoperative serum levels of MACC1 protein in various tissue types.

\begin{tabular}{lcc}
\hline Tissue type & No. of samples & $\begin{array}{c}\text { MACC1 } \\
\text { serum levels } \\
(\mathrm{pg} / \mathrm{ml})\end{array}$ \\
\hline Normal ovarian control & 20 & $33.209 \pm 5.34$ \\
Ovarian benign tumor & 25 & $37.71 \pm 7.61$ \\
Epithelial ovarian cancer & 47 & $89.01 \pm 11.24^{\mathrm{a}}$ \\
\hline
\end{tabular}

${ }^{a}$ Values presented as mean $\pm \mathrm{SD} .{ }^{\mathrm{b}} \mathrm{P}<0.05$ vs. normal and benign groups. MACC1, metastasis-associated in colon cancer.

those in epithelial benign tumor tissues $(28.00,25.00$ and $36.00 \%$, respectively) and normal ovarian epithelial tissues (5.00, 5.00 and 10.00\%, respectively) (Table III; P<0.05).

Correlations between MACCl expression in tumor tissue and clinicopathological parameters. Within the ovarian tumor group, MACC1 expression in tumor tissues from patients with lymph node metastases was significantly greater than that in patients without lymph node metastasis $(\mathrm{P}<0.05$; Table IV). Significant associations were also identified between MACC1 expression and clinical stage and histological grade $(\mathrm{P}<0.05)$, but not histological type $(\mathrm{P}>0.05)$. The expression of HGF and c-Met in ovarian epithelial malignant tumor tissues were 
Table VI. Correlations between preoperative serum MACC1 levels and clinicopathological features of patients with ovarian malignant epithelial tumors (mean $\pm \mathrm{SD}, \mathrm{pg} / \mathrm{ml}$ ).

\begin{tabular}{|c|c|c|c|c|}
\hline Clinical parameter & No. patients & $\begin{array}{l}\text { Serum MACC1 levels } \\
(\mathrm{pg} / \mathrm{ml})\end{array}$ & $\mathrm{t} / \mathrm{F}$ & $\mathrm{P}$-value ${ }^{\mathrm{a}}$ \\
\hline Age (years) & & & 0.790 & 0.434 \\
\hline$<45$ & 11 & $91.71 \pm 11.94$ & & \\
\hline$\geq 45$ & 36 & $88.76 \pm 10.79$ & & \\
\hline FIGO stage & & & -2.182 & 0.034 \\
\hline $\mathrm{I}+\mathrm{II}$ & 10 & $82.92 \pm 10.90$ & & \\
\hline III+IV & 37 & $90.93 \pm 10.10$ & & \\
\hline Histological type & & & 0.884 & 0.420 \\
\hline Serous & 30 & $87.88 \pm 10.46$ & & \\
\hline Mucinous & 10 & $93.03 \pm 10.76$ & & \\
\hline Endometrioid & 7 & $90.81 \pm 13.84$ & & \\
\hline Histological grading & & & 2.877 & 0.006 \\
\hline High differentiation & 30 & $86.17 \pm 9.37$ & & \\
\hline Low differentiation & 17 & $95.12 \pm 11.64$ & & \\
\hline Lymph node metastasis & & & 2.076 & 0.044 \\
\hline Positive & 29 & $91.95 \pm 11.35$ & & \\
\hline Negative & 18 & $85.32 \pm 9.36$ & & \\
\hline
\end{tabular}

a(?). MACC1, metastasis-associated in colon cancer.

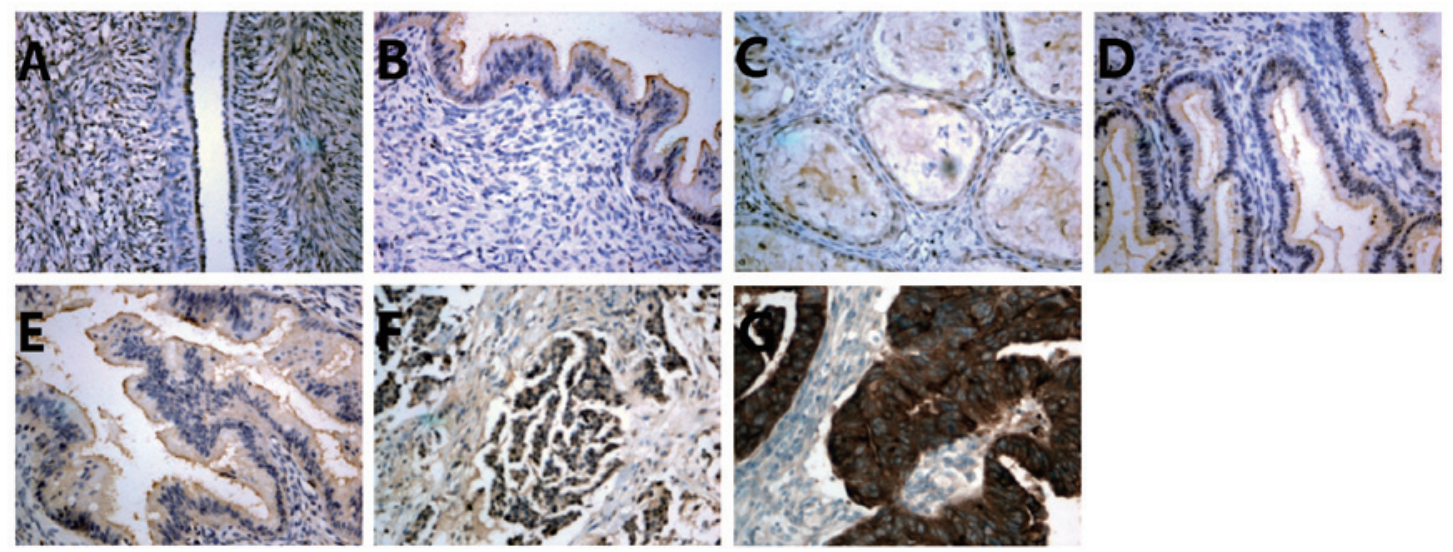

Figure 3. Locations of metastasis-associated in colon cancer-1 (MACC1), hepatocyte growth factor (HGF) and c-Met proteins in normal ovarian epithelium, benign epithelial ovarian tumor and epithelial ovarian carcinoma tissue samples, examined using immunohistochemistry. (A) Negative expression of MACC1 in normal ovarian tissue. (B) Positive expression of MACC1 in ovarian benign epithelial tumor tissue. (C) Positive expression of HGF in benign epithelial tumor tissue. (D) Positive expression of c-Met in benign epithelial tumor tissue. (E) Positive expression of MACC1 in epithelial ovarian cancer. (F) Positive expression of HGF in epithelial ovarian cancer. (G) Positive expression of c-Met in epithelial ovarian cancer (stain, avidin-biotin-peroxidase complex; magnification, $\mathrm{x} 400$ ).

also higher in tumor tissues with lymph node metastasis than those without lymph node metastasis $(\mathrm{P}>0.05)$. A significant positive correlation was identified between the expression levels of HGF and c-Met $(\mathrm{P}<0.01)$.

Correlation between serum MACC1 levels and clinicopathological parameters. Using ELISA, the preoperative serum MACC1 levels (Table V) in the malignant tissues were significantly different compared with those of the corresponding normal control tissues (Wilcoxon rank-sum test, $\mathrm{z}=-6.440$, $\mathrm{P}<0.001)$ and tissues from patients with benign ovarian tumors $(\mathrm{z}=-6.949, \mathrm{P}<0.001)$. Furthermore, in the malignant tissue group, the preoperative serum MACC1 levels were significantly higher than the postoperative levels $(\mathrm{P}<0.05)$. Notably, a significant association was identified between the preoperative serum MACC1 levels and International Federation of Gynecology and Obstetrics (FIGO) stage and lymph node metastasis (Table VI). 


\section{Discussion}

In the present study, the expression levels of MACC1 and $\mathrm{HGF} / \mathrm{c}-$ Met mRNA were significantly higher in epithelial ovarian cancer tissues than in normal ovarian and benign epithelial ovarian tumor tissues. Further evaluation of these data sets indicated that MACC1, HGF and c-Met mRNA expression levels were interrelated in the epithelial ovarian tumor tissue $(\mathrm{P}<0.01)$. Notably, previous studies have shown that MACC1 and HGF/c-Met levels were correlated; a positive feedback loop was identified between MACC1 and $\mathrm{HGF} / \mathrm{c}-\mathrm{Met}$, which is involved in multiple cellular responses $(10,16)$. This is consistent with the experimental data from the present study. Therefore, MACC1 may be involved in the occurrence and development of ovarian cancer, and associated with the biological behavior of ovarian cancer cells.

Further investigation may determine the underlying mechanism by which MACC1 affects HGF and c-Met expression in epithelial ovarian cancer. In the present study, MACC1 and tyrosine kinase encoded by the c-Met oncogene, as well as the corresponding ligand HGF, were found to be expressed not only in epithelial ovarian tumors, but also in normal ovarian tissues. However, the expression of these factors was higher in the epithelial ovarian tumor tissue compared with the normal ovarian tissue and benign epithelial tumor tissue. The findings from the present study are consistent with the previous detection of high expression levels and cytoplasmic location of MACC1 in colon cancer tissue (13). Previous studies have also demonstrated the potential role of c-Met family receptor coexpression in promoting ovarian cancer cell invasiveness, and have suggested that these molecules may be indicators of cancer progression and markers of tumor cell propensity to metastasize $(20,22)$. In the present study, MACC1, HGF and c-Met expression was associated with advanced FIGO stage, poor differentiation and lymph node metastasis in epithelial ovarian cancer $(\mathrm{P}<0.05)$. The data suggest that the expression and cellular location of MACC1 may be useful in predicting ovarian cancer progression and metastasis. Furthermore, previous studies also observed that MACC1 increases c-Met protein transcription and translation, and then activates the HGF/Met signaling pathways, enhancing cancer cell proliferation and migration, and promoting the invasion and metastasis of colon cancer cells (14,20-25). An increasing number of studies have demonstrated that tumor invasion and metastasis is closely associated with the overexpression of MACC1 in various types of tumor, including colon, gastric, liver and lung cancer $(10,26,27)$. Thus, we propose that MACC1 protein expression may also affect ovarian cancer progression.

The serum levels of MACC1 expression in benign and malignant ovarian tumors and a normal control tissues were investigated in the present study. The results show that the MACC1 serum levels in the ovarian malignant epithelial neoplasm group was significantly higher than those of the benign epithelial tumor and normal control groups. In addition, the preoperative serum MACC1 levels in the malignant tumor group were significantly associated with the depth of invasion, clinical stage, histological grade and lymph node metastasis $(\mathrm{P}<0.05)$. Therefore, MACC1 serum levels in ovarian cancer patients may be closely associated with the course of the disease. Significant differences in the preoperative and postoperative serum levels of MACC1 were detected $(\mathrm{P}<0.05)$; this indicates that serum MACC1 levels were rapidly reduced in the optimal cytoreductive surgery. Linear regression analysis revealed that the increased MACC1 expression levels in ovarian malignant epithelial neoplasm tissues were significantly correlated with increased MACC1 serum concentrations $(\mathrm{r}=0.870, \mathrm{P}<0.05)$. The overlap between high predicted MACC1 levels and experimentally confirmed MACC1 expression levels in ovarian cancer tissues supports this conclusion $(24,25)$. Whether serum MACC1 levels may be a novel tumor marker in the diagnosis and follow-up of ovarian malignant epithelial tumors requires further investigation. In conclusion, MACC 1 expression in normal, benign and malignant tissues may provide the foundation for the development of innovative metastasis intervention strategies using MACC1 as a therapeutic target.

\section{Acknowledgements}

The authors would like to thank the management and professional staff of the following three sites that processed samples: The Department of Gynecological Oncology, the Pathological Diagnostic Laboratory of the Third Affiliated Hospital of Zhengzhou University and the Key Laboratory of Gynecological Oncologists of Zhengzhou City. The authors would also like to thank Professor Yuping Wang for assistance in the pathological review of specimens, Ms Lili Dong for assisting in the preparation of this manuscript and all patients involved in this study.

\section{References}

1. Jemal A, Siegel R, Xu J and Ward E: Cancer statistics, 2010. CA Cancer J Clin 60: 277-300, 2010.

2. Parkin DM, Bray F, Ferlay J and Pisani P: Global cancer statistics, 2002. CA Cancer J Clin 55: 74-108, 2005.

3. Gu M and Shi W: Current Research Management of Ovarian Cancer in China. The Chinese German Journal of Clinical Oncology 4: 212-218, 2002.

4. Shen K: The progress and challenge of chemotherapy in ovarian cancer. Chin J Clin Obstet Gynecol 2002: 3-7, 2002.

5. Qiu J, Huang P, Liu Q, et al: Identification of MACC1 as a novel prognostic marker in hepatocellular carcinoma. J Transl Med 9: 166, 2011.

6. Ponzo MG, Lesurf R, Petkiewicz S, et al: Met induces mammary tumors with diverse histologies and is associated with poor outcome and human basal breast cancer. Proc Natl Acad Sci USA 106: 12903-12908, 2009.

7. Cappuzzo F, Marchetti A, Skokan M, et al: Increased MET gene copy number negatively affects survival of surgically resected non-small-cell lung cancer patients. J Clin Oncol 27: 1667-1674, 2009.

8. Stein U, Dahlmann M and Walther W: MACC1-more than metastasis? Facts and predictions about a novel gene. J Mol Med (Berl) 88: 11-18, 2010.

9. Regauer S and Reich O: CK17 and p16 expression patterns distinguish (atypical) immature squamous metaplasia from highgrade cervical intraepithelial neoplasia (CINIII). Histopathology 50: 629-635, 2007.

10. Boardman LA: Overexpression of MACC1 leads to downstream activation of HGF/MET and potentiates metastasis and recurrence of colorectal cancer. Genome Med 1: 36, 2009.

11. Liang P and Pardee AB: Differential display of eukaryotic messenger RNA by means of the polymerase chain reaction. Science 257: 967-971, 1992

12. Stein U, Walther W, Arlt F, et al: MACC1, a newly identified key regulator of HGF-MET signaling, predicts colon cancer metastasis. Nat Med 15: 59-67, 2009.

13. Chundong G, Uramoto H, Onitsuka T, et al: Molecular diagnosis of MACC1 status in lung adenocarcinoma by immunohistochemical analysis. Anticancer Res 31: 1141-1145, 2011. 
14. Stein U, Smith J, Walther W and Arlt F: M ACC 1 controls Met - what a difference an Spl site makes. Cell Cycle 8: 2467-2469, 2009.

15. Birchmeier C, Birchmeier W, Gherardi E and Vande Woude GF: Met, metastasis, motility and more. Nat Rev Mol Cell Biol 4: 915-925, 2003.

16. Arlt F and Stein U: Colon cancer metastasis: MACC 1 and Met as metastatic pacemakers. Int J Biochem Cell Biol 41: 2356-2359, 2009.

17. Chirgwin JM, Przybyla AE, MacDonald RJ and Rutter WJ: Isolation of biologically active ribonucleic acid from sourses enriched in ribonuclease. Biochemistry 18: 5294-5299, 1979.

18. Ferracini R, Di Renzo MF, Scotlandi K, et al: The Met/HGF receptor is over-expressed in human osteosarcomas and is activated by either a paracrine or an autocrine circuit. Oncogene 10: 739-749, 1995.

19. Schmittgen TD and Livak KJ: Analyzing real-time PCR data by the comparative C(T) method. Nat Protoc 3: 1101-1108, 2008

20. Huntsman D, Resau JH, Klineberg E and Auersperg N: Comparison of c-met expression in epithelial ovarian tumors and normal epithelial of the female reproductive extract by quantitative laser scan microscopy. Am J Pathol 155: 343-348, 1999.
21. Maggiora P, Lorenzato A, Fracchioli S, et al: The RON and MET oncogenes are co-expressed in human ovarian car cinemas and cooperate in activating invasiveness. Exp Cell Res 288: 382-389, 2003.

22. Sattler M and Salgia R: c-Met and hepatocyte growth factor: potential as novel targets in cancer therapy. Curr Oncol Rep 9: 102-108, 2007.

23. Bottaro DP, Rubin JS, Faletto DL, et al: Identification of the hepatocyte growth factor receptor as the c-met proto-oncogene product. Science 251: 802-804, 1991.

24. Chmielowiec J, Borowiak M, Morkel M, et al: c-Met is essential for wound healing in the skin. J Cell Biol 177: 151-162, 2007.

25. Kaposi-Novak P, Lee JS, Gòmez-Quiroz L, et al: Met-regulated expression signature defines a subset of human hepatocellular carcinomas with poor prognosis and aggressive phenotype. J Clin Invest 116: 1582-1595, 2006.

26. Shirahata A, Sakata M, Kitamura Y, et al: MACC 1 as a marker for peritoneal-disseminated gastric carcinoma. Anticancer Res 30: 3441-3444, 2010

27. Shirahata A, Fan W, Sakuraba K, et al: MACC 1 as a marker for vascular invasive hepatocellular carcinoma. Anticancer Res 31: 777-780, 2011. 